\title{
One Size Does Not Fit All: Traditional and Innovative Models of Student Affairs Practice
}

\author{
Edited by Kathleen Manning, Jillian Kinzie, and John H. Schuh, \\ Routledge, London, first edition, February 22, 2006; \\ ISBN: 0415952581; \$34.95; 200pp
}

International Journal of Educational Advancement (2008) 8, 47-48. doi:10.1057/ijea.2008.4

The field of higher education and student affairs constantly changes and develops with the change in society. Practitioners need to continually adapt methods and practice in order to be effective and positively affect student development. Several current models or methods exist in the field while innovative methods develop as a result of research. In One Size Does Not Fit All: Traditional and Innovative Models of Student Affairs Practice, the authors attempt to provide a review and analysis of existing and potential future methods.

The authors divided this book into four sections attempting to make it easier to digest by the reader. The introduction section focuses on discussing the changing methods of organizing student affairs and the relationship to students. The second part of the book discusses traditional models of student affairs administrations while the third section discusses innovative models based upon completed research. The final part discusses the incorporation of student affairs and the potential future of the department and practice.

The three authors discovered the need for examining different practices of student affairs at different institutions. By participating in the Documenting Effective Educational Practices (DEEP) project, the authors discovered how practitioners at different types of institution perceive student affairs differently (Manning et al., 2006). This book attempts to document the multiple types of methods and theories in one location for easy use by current and future student affairs practitioners.

Essentially, minus the introduction and conclusion, student affairs methods and theory are divided into two main categories, traditional and innovative (Manning et al., 2006). The section discussing traditional methods includes information on established models based on out-of-classroomcentered, administrative-centered, and learning-centered methods.

While discussing each of the established models, the authors provide 
additional information regarding the individual model itself in terms of history, theory basis, and diagrams that assist in the explanation of the corresponding theory. The diagrams provide the reader with a clear picture for the hierarchy of specific officials involved in the implementation of student affairs within that model or method.

The third section of the book contains descriptions of the innovative methods, developed from research compiled by the DEEP project. The innovative methods proposed contain two sub-categories of student-centered and academic and collaboration models (Manning et al., 2006). By dividing the section into chapters based upon the focus of the proposed methods or models, the authors utilize the chapters to describe the strengths of the innovative models.

As this book contains more of a compilation of pre-existing information, describing the "results" of their research becomes difficult. The book contains a logical organization of information for the practitioner. The author occasionally sprinkles examples of institutions that use the model being described.

The contribution made to the existing literature by this book is beneficial as a reference for current and future student affairs practitioners.
The authors recognize the history of student affairs and respect foundation of researchers prior to them. As a result of the research by the DEEP project, new methods of implementing student affairs practices are suggested and provide the reader with possible solutions to the changing face of student affairs administration.

The authors prove that they have a strong knowledge of the subject matter being discussed. The categorization of the models allows the reader to use the publication as an easy reference when researching his or her institution. The authors also provide a critical analysis including strengths and weaknesses of methods being discussed. The authors add validity to the methods by providing expert analysis for implementation.

Overall, this book provides additional information for student affairs practitioners. While implementing student affairs activities into practice may be difficult, the authors provide a useful reference for practitioners to identify methods that may be useful at their institutions.

Rachel Meseke
Peabody College, Vanderbilt
University, Box 514-GPC,
230 Appleton Place, Nashville,
TN 37203, USA

Rachel Meseke University, Box 514-GPC, TN 37203, USA 